Accuracy and bias in the social perception of envy

\author{
Jens Lange ${ }^{\mathrm{a} *}$, Birk Hagemeyer ${ }^{\mathrm{b} *},{\text { Thomas } \operatorname{Lösch}^{\mathrm{c}}, \& \text { Katrin Rentzsch }}^{\mathrm{d}, \mathrm{e}}$ \\ ${ }^{a}$ University of Amsterdam, ${ }^{b}$ Friedrich Schiller University Jena, ${ }^{c}$ DIPF | Leibniz Institute for \\ Research and Information in Education ${ }^{\mathrm{d}}$ University of Bamberg, ${ }^{\mathrm{e}}$ Bamberg Graduate School \\ of Affective and Cognitive Sciences (BaGrACS)
}

\title{
in press at Emotion
}

* Both authors contributed equally to this manuscript

Correspondence should be addressed to either Jens Lange, University of Amsterdam, Department of Social Psychology, P.O. Box 15900, 1001 NK Amsterdam, The Netherlands, E-Mail: j.lange2@uva.nl, or Birk Hagemeyer, Friedrich-Schiller-University, Institute of Psychology, Humboldtstraße 11, D-07743 Jena, Germany. E-Mail: birk.hagemeyer@unijena.de.

The research reported in this article was supported by grants from the German Research foundation (DFG, Deutsche Forschungsgemeinschaft) awarded to Jens Lange (LA 4029/1-1) and Katrin Rentzsch (RE 3718/3-1). We thank Florian Wanders for feedback on a previous version of this manuscript. We thank Alina Feldotto, Yvonne Freytag, Lucia Gehlen, Jana Harzem, Vera Hebel, Jana Hohnsbehn, Tessa Kohlberg, Sarah Kox, Susann Lorenz, Nico Noack, Anika Preik, Nora Schumacher, and Rebecca Stein for their help with data collection and Nele Wolf for her help in developing Study 2 as well as for collecting data. 


\begin{abstract}
Research converges on the notion that when people feel envy, they disguise it towards others. This implies that a person's envy in a given situation cannot be accurately perceived by peers, as envy lacks a specific display that could be used as a perceptual cue. In contrast to this reasoning, research supports that envy contributes to the regulation of status hierarchies. If envy threatens status positions, people should be highly attentive to identify enviers. The combination of the two led us to expect that (a) state envy is difficult to accurately perceive in unacquainted persons and (b) dispositional enviers can be accurately identified by acquaintances. To investigate these hypotheses, we used actor-partner interdependence models to disentangle accuracy and bias in the perception of state and trait envy. In Study 1, 436 unacquainted dyad members competed against each other and rated their own and the partner's state envy. Perception bias was significantly positive, yet perception accuracy was non-significant. In Study 2, 502 acquainted dyad members rated their own and the partner's dispositional benign and malicious envy as well as trait authentic and hubristic pride. Accuracy coefficients were positive for dispositional benign and malicious envy and robust when controlling for trait authentic and hubristic pride. Moreover, accuracy for dispositional benign envy increased with the depth of the relationship. We conclude that enviers might be identifiable but only after extended contact and discuss how this contributes to research on the ambiguous experience of being envied.
\end{abstract}

Keywords: benign and malicious envy; self-other agreement; actor-partner interdependence model; accuracy and bias in person perception 
Accuracy and bias in the social perception of envy

It is a widely shared conviction that enviers disguise their experience (Smith, 2004). Theorizing implies that envy is not admitted to others and that there may be no distinct facial expression or bodily display (Miceli \& Castelfranchi, 2007; Smith \& Kim, 2007). However, people can report on situations in which they have been envied (Rodriguez Mosquera, Parrott, \& Hurtado de Mendoza, 2010). This suggests that there are ways to identify enviers.

In fact, there might be. Anthropological evidence implies that envy is sometimes strategically expressed or elicited with the intention to manipulate people (Foster, 1972). For instance, advertisements often display enviers who seemingly want to obtain the product themselves. Beyond these strategic situations, theorizing suggests that envy can manifest in symbolic behavior, which helps to identify the envious (Foster, 1972). In the only study on the perception of envy so far, observers inferred envy if an inferior person uttered rude comments about a superior, befriended person in front of an uninvolved third party (Silver \& Sabini, 1978). Yet, such inferences might not reflect accurate perceptions of envy, but rather the perceiver's subjective theory of the conditions that elicit envy. In real life, given their undesirable nature, envy-driven reactions may rarely manifest in behavior, may be kept private, or potentially transmute into more socially desirable reactions such as indignation and schadenfreude (Smith, 2004; Smith \& Kim, 2007). Thus, is it possible to identify enviers?

We argue that it is. Recent research supports that envy contributes to the regulation of status hierarchies (Crusius \& Lange, 2017; Fiske, 2010; Lange \& Crusius, 2015b; Lange, Crusius, \& Hagemeyer, 2016). After a painful upward status comparison, enviers can improve their own standing — which is called benign envy — or try to harm the superior's positionwhich is called malicious envy (Falcon, 2015; Van de Ven, Zeelenberg, \& Pieters, 2009). These benign and malicious inclinations guide enviers' thoughts, feelings, and actions over extended periods of time (Lange, Weidman, \& Crusius, 2018). Therefore, envy is a temporally enduring status threat for others. Given that a desire to attain and keep status is a 
fundamental human motive, people are highly attentive to such threats (Anderson, Hildreth, \& Howland, 2015).

As envy may have no distinct facial expression (Smith \& Kim, 2007), it is likely difficult to recognize it in a specific situation, especially with unacquainted persons. That is, even if people are attentive to status threats, the social perception of envy is difficult given the lack of a distinct display. Instead, enviers should rather be identifiable after extended contact as persons can only learn over time about others' envious inclinations. That is, even if envy may not have a distinct display, this is not to say that there are no hints to people's envy. The social perception of envy may be possible via contextual information (e.g., the presence of a successful other) in contingency with the perception of affective responses expressed by the envier (e.g., negative affect). Identifying such contingencies requires accumulating information across multiple situations and may facilitate the identification of enviers over time. We propose that such contingencies constitute people's dispositional tendencies to react with envy across situations. Thus, we expected that envy can be accurately perceived by acquainted raters at the level of stable traits, but it would be challenging to do so by unacquainted raters at the level of situational states.

To test this, we applied a paradigm that is frequently used in personality research, but only rarely in emotion research, namely the assessment of self-other agreement (Watson, Hubbard, \& Wiese, 2000). Specifically, we applied the actor-partner interdependence model (APIM; e.g., Kenny \& Acitelli, 2001; Kenny, Kashy, \& Cook, 2006; Neyer, Banse, \& Asendorpf, 1999). In this model, self-ratings of a variable are related to peer-ratings of the same variable within dyads of participants. Each peer-rating is predicted by both partners' self-ratings of the same variable (see explanatory Figure 1). In the current studies, Partners 1 and 2 rated themselves and each other on envy. Both self-ratings of envy then predicted both partner ratings. 
The APIM allows to parse self-other agreement (i.e., the correlation of self- and peer-rating) into two processes (Kenny \& Acitelli, 2001). First, there may be perception accuracy. This would be reflected in a positive relationship of persons' self-ratings with the ratings by the partners (i.e., the peer-ratings) controlling for the partners' self-ratings. This constitutes the direct effect explaining self-other agreement. Second, there may be a bias to rate others according to the self. This would be reflected in a positive relationship of persons' self-ratings with these persons' ratings of the partners, controlling for partners' self-ratings. If there is actual similarity, that is, a positive correlation between dyad members' self-ratings, then this bias contributes to self-other agreement. Conversely, if there is no actual similarity, then the bias cannot contribute to self-other agreement. Put differently, if only the self-other correlation is examined, it may appear that partner values can be correctly predicted even though the prediction was not based on accurate perception, but on similarity bias. Therefore, the product of bias and actual similarity constitutes the indirect effect explaining self-other agreement. Thus, the APIM disentangles (a) the contribution of accuracy and (b) the combined effect of bias and actual similarity in the perception of states or traits.

\section{The Current Research}

We applied the APIM to investigate whether enviers are identifiable (i.e., can be accurately perceived). We compared the following hypotheses. If enviers are unidentifiable, perception accuracy of envy should be zero. In contrast, if, as we theorize, envy manifests in recognizable threats to observers' status across situations, perception accuracy should be positive. Moreover, perception accuracy should be higher the more information the partners have about each other.

We conducted two studies. In Study 1, we analyzed the social perception of envy at the level of situational states with unacquainted dyads of participants after a short interaction in the lab. This constitutes a situation in which, according to our theorizing, the perception of envy is rather difficult. Participants had no prior experience with each other and there were 
only few instances that could potentially elicit envy in the partner. In Study 2, we investigated the social perception of envy in acquainted dyads with dispositional ratings of envy instead of state ratings. Expanding Study 1, we assessed benign and malicious forms of envy and compared the accurate identification of enviers with the accurate identification of proud individuals.

Taken together, the two studies complement each other in drawing a complete picture of the social perception of envy. Study 1 provides a test whether the contingencies between contextual and personal cues necessary to identify enviers can be perceived already after a short interaction such that state envy is accurately perceived. Study 2 complements this approach because traits and states are functionally related. First, traits manifest as states in given situations. Evidence supports that dispositional (benign and malicious) envy predicts state envy (Lange \& Crusius, 2015a), even beyond neuroticism, self-esteem, hostility, desirable responding, or other emotions such as sadness and anger (Rentzsch \& Gross, 2015; Smith, Parrott, Diener, Hoyle, \& Kim, 1999). Second, theorizing and evidence are in line with the notion that traits can be conceptualized as aggregated states over a variety of situations (for a review see Fleeson \& Jayawickreme, 2015). That is, traits represent the expected value of a distribution of states. We argue that the functional association between states and traits is mirrored in the association between peer-perceived states and peer-perceived traits. As such, the identification of dispositional enviers may represent a person's accumulated information about another person's envious inclinations over extended periods of time. Given that such larger samples of experiences are more reliable, there should be positive accuracy coefficients for dispositional envy in Study 2. Conversely, perception accuracy of state envy after a single short interaction as in Study 1 will be difficult to achieve for observers.

In the present studies, we report all data exclusions, manipulations, and measures. The de-identified data, analysis scripts, and materials are available on the Open Science Framework (OSF; https://osf.io/wjuya/?view_only=eb8ef61066fd47c28aaa62d27215b452). 


\section{Study 1}

The goal of Study 1 was to investigate whether state envy can be accurately perceived in unacquainted dyads after a short interaction. To this end, we used data from the PESI (Personality and Emotions in Social Interactions) study (Rentzsch \& Lösch, 2018). This is a larger project on the social nature of envy. Here, we describe the part of the design central for our hypothesis tests. The entire materials and procedure are described on the OSF (osf.io/2uf7a/). Even though data collection was already finished, we nevertheless preregistered our analysis plan on the OSF prior to analyzing the data (osf.io/w3p8q).

\section{Method}

Participants. Dyads of unacquainted participants, which were matched with respect to gender and age, were investigated in the lab. In total, 468 participants ( 234 dyads) took part in the study. Sixteen dyads were excluded based on preregistered criteria. Eight of these dyads were excluded because participants knew each other too well. The exclusion criterion was a value of at least 4 on the item "How well do you know the other person?" answered on a scale of 1 (not at all) to 7 (very much). We also excluded four dyads in which one interaction partner encountered language problems and four dyads in which the actual procedure strongly deviated from the planned procedure (i.e., three dyads were excluded because they did not follow instructions; one dyad was excluded because of technical problems). The mean age of the final sample of 436 participants (218 dyads) was 31.2 years $(S D=14.0$, range: $16-75)$. One hundred and fourteen participants were male. With respect to educational attainment, 59 participants had a middle school degree (German Mittlere Reife), 27 a high school degree (Abitur), 191 a high school degree and a current status as college or university student, 157 a college or university degree, and two participants were without an academic degree. The targeted sample size and exclusion criteria were preregistered in the PESI study (osf.io/w3p8q). Post-hoc power analysis indicated that the sample size provided $95 \%$ power to detect small to medium-sized accuracy and bias effects of $\beta=.25$ with $\alpha=.05$ (two-tailed), 
given common specifications for an APIM with distinguishable dyads (Ackerman \& Kenny, 2016).

Materials and procedure. Participants interacted in two different competitive situations. This allowed us to investigate the social perception of envy twice, increasing the strength of the conclusions drawn from the study. Participants first competed in dyads in a game called rock-paper-scissors. The task had been pretested for eliciting envy in losers (Rentzsch \& Gross, 2015). The rules of the game were provided on a sheet of paper. In a round, each participant picked one of the options (i.e., rock, paper, or scissors). Rock beats scissors, but loses against paper. Paper beats rock, but loses against scissors. Participants completed three test rounds to get acquainted with the game. Afterwards, the game started. Participants were informed that the game is finished when a participant wins a round and that the winner receives a small monetary reward. The reward was a $€ 10$ note that was placed in an opaque box next to both participants. Till the end of the study, the note should be left on the table next to the participant who had just won the game. Subsequently, both partners used the same three items to (a) rate their envy toward the partner at the present moment and to (b) rate how envious they perceive the partner to be toward them at the present moment. The items were "I am/The person is a little envious of the person/me", "I/The person envy/envies the person/me", and "I/The person feel/s envy". Responses were provided on a scale from 1 (does not apply at all) to 7 (applies strongly).

Subsequently, participants worked together on the lost-on-the-moon task (e.g., Robins \& Beer, 2001). They had to imagine that they had crashed on the moon far away from their mothership. Only 14 items were left, and the task was to individually sort them in terms of importance for survival. Then, participants traded resources with each other to attain the best selection of items for themselves. Following the task, they again completed the same items to rate their own and the partner's envy. All scales were reliable (see Table 1).

\section{Results}


In the analyses, participants were assigned to the roles of Partner 1 or 2 based on whether they won or lost the rock-paper-scissors game, respectively. As preregistered, the assignments for the lost-on-the-moon task were also based on the results of the rock-paperscissors game. In the lost-on-the-moon task, partners initially generated solutions individually and subsequently, they negotiated a final solution. During the study, partners did not receive any performance feedback. Therefore, no explicit comparison between them was possible. We expected that not winning $€ 10$ because of losing the rock-paper-scissors game would be the central elicitor of envy. Therefore, losing the rock-paper-scissors game may carry over to the lost-on-the-moon task.

Table 1 shows descriptive statistics for winners and losers, zero-order correlations for winners and losers, and within-dyad correlations. The within-dyad correlations of all variables were not significant, yet self-ratings correlated with ratings of the partner. In order to analyze whether participants perceived the situation on average as intended, we compared winners (1) and loser (-1) regarding their self- and peer-ratings of envy separately for each task. Specifically, we conducted linear mixed models with participants nested within dyads and a random intercept for each dyad. Indeed, losers were on average significantly more envious than winners in the rock-paper-scissors game, $B=-0.96, S E=0.10, t(217.20)=-9.61$, $p<.001$, and marginally so in the lost-on-the-moon task, $B=-0.14, S E=0.08, t(434)=-1.79$, $p=.07$. This pattern was mirrored in the peer ratings. That is, winners rated losers on average to be more envious after the rock-paper-scissors game than losers rated winners, $B=0.98, S E$ $=0.10, t(418)=10.11, p<.001$. For the lost-on-the-moon task, however, peer-ratings did not differ significantly, $B=-0.001, S E=0.07, t(212.05)=-0.02, p=.99$.

We investigated our predictions with APIMs using structural equation modeling and full information maximum likelihood estimation to treat missing data. We specified separate APIMs for the rock-paper-scissors game and the lost-on-the-moon task parsing self-other agreement into accuracy, bias, and actual similarity (Figure 1). We estimated all means, 
intercepts, paths, and (co)variances. Therefore, the initial models were saturated. All variables were $z$-standardized at their grand means and variances before the analyses.

We focused mainly on accuracy and bias regarding the perception of losers' envy. This is because winners had less envy overall, potentially leading to variance reduction (Table 1). However, as preregistered, we tested whether setting winners' and losers' accuracy paths to be equal resulted in a significant decrease in model fit. As shown in Table 2, it did not, for neither the rock-paper-scissors game nor the lost-on-the-moon task, applying conventional standards (Hu \& Bentler, 1999). Therefore, we interpreted only the models in which this constraint was set. The results of all model tests are displayed in Table 2.

Perception accuracy was low and non-significant in both the rock-paper-scissors game and the lost-on-the-moon task. In contrast, perception biases were all positive and significant, except for losers' bias in the rock-paper-scissors game. As actual similarity was non-significant, this bias, however, did not contribute to self-other agreement.

As accuracy and the combined effect of bias and actual similarity together constitute self-other agreement, we can estimate self-other agreement from these models. That is, selfother agreement equals the accuracy path plus the product of bias and actual similarity (Kenny \& Acitelli, 2001). Self-other agreement of winners and losers regarding losers' envy was $r=.061, S E=.05, p=.22,95 \%$ CI [-.037, .160] for the rock-paper-scissors game and $r=$ $-.022, S E=.057, p=.71,95 \%$ CI $[-.134, .091]$ for the lost-on-the-moon task. Self-other agreement of winners and losers regarding winners' envy was $r=.041, S E=.048, p=.39$, $95 \% \mathrm{CI}[-.054, .136]$ for the rock-paper-scissors game and $r=-.014, S E=.048, p=.76,95 \%$ CI $[-.108, .079]$ for the lost-on-the-moon task.

\section{Discussion}

In Study 1, we found no evidence that state envy can be accurately perceived by unacquainted partners. Participants were only biased to rate the partner in line with their own experience. There was also no evidence for self-other agreement for perceiving winners' and 
losers' envy. But, on average, winners rated losers to be more envious in the rock-paperscissors game than losers rated winners. It therefore seems that situational differences between winners and losers are reflected in peer ratings of envy, but individual differences in envious responses could not be identified above chance level. Put differently, participants correctly indicated that losing would make persons in general more envious than winning, yet they did not accurately perceive which persons were more envious than others.

The lack of significant accuracy effects in Study 1 is consistent with our expectation that state envy can hardly be perceived when raters have only limited information about the other person at hand. It could be, as we theorize, that envy is more accurately perceived after extended contact. This would require that the inclination to react with envy is somewhat consistent across situations. This is supported in Study 1. Self-rated envy was strongly and positively correlated across the rock-paper-scissors game and the lost-on-the-moon task (Table 1). Such consistency can indicate dispositional tendencies to experience envy, which have been reported to show high retest stability over multiple weeks (e.g., Lange \& Crusius, 2015a; Rentzsch \& Gross, 2015). Dispositional envy might be more accurately perceived, as such partner ratings integrate information about a person's envy over multiple situations. Moreover, the identification of acquainted enviers should be more accurate than the perception of envy by an unacquainted other in a specific situation. Therefore, to complement Study 1, we investigated the identification of enviers in Study 2, using a measure of dispositional envy and acquainted dyads.

\section{Study 2}

The goal of Study 2 was to investigate the social perception of envy in acquainted dyads using a measure of dispositional instead of state envy. Study 2 therefore provides a test of the hypothesis that enviers can be accurately identified by acquainted others. Next to using dispositional envy, we additionally tested whether in relationships, in which partners know each other better, accuracy is higher. 
Study 2 is also different in some other respects. As a first change, we used a different measure of envy. In Study 1, we assessed envy on a more general level using items referring to the emotion label. As emotions are multi-componential responses (e.g., feeling, cognition, motivation) to social challenges and opportunities (Niedenthal \& Ric, 2017), they can also be assessed more concretely at the level of emotion components. These different levels of analysis imply different kinds of measures for envy. In fact, even though envy is a painful emotion to experience, it manifests in qualitatively different ways (Lange et al., 2018). In benign envy, the pain is accompanied by desire for the envy object, improvement motivation, and emulation of the envied person, whereas in malicious envy, the pain is accompanied by aggressive feelings, thoughts, and motivations. Although benign and malicious envy are both positively related to envy measures based on the emotion label (e.g., Lange \& Crusius, 2015b), they are largely independent from each other (Lange \& Crusius, 2015a; Lange et al., 2018). Measuring envy at the level of its components therefore requires separating its benign and malicious forms. In line with this, we complemented Study 1 by measuring benign and malicious envy in Study 2. Because of their common foundation in painful upward comparisons, we expected perception accuracy for both forms of dispositional envy.

As a second change, we also assessed trait pride. Envy and pride are both related to the regulation of status hierarchies. Envy is functional for addressing status threats (Crusius \& Lange, 2017) and pride signals high status to observers (Shariff \& Tracy, 2009). In line with these complementary functions, evidence supports that pride and envy are intertwined such that successful persons' pride increases inferiors' envy (Lange \& Crusius, 2015b). Moreover, people characterized by higher status desires (e.g., people higher in grandiose narcissism) are more likely to experience envy (Lange et al., 2016) and pride (Rogoza, Kwiatkowska, Kowalski, \& Ślaski, 2018).

Given their shared features, taking pride into account can clarify the social perception of envy in two ways. First, accuracy in the social perception of pride can be 
compared to accuracy in the social perception of envy. In contrast to envy, pride has a recognizable display (Tracy \& Robins, 2007a) and, consequentially, research supports positive self-other agreement for trait pride (Liu, Yuan, Chen, \& Yu, 2016). Even though accuracy and bias have not been disentangled for trait pride in previous studies, this reasoning suggests that proud individuals can be more accurately identified than enviers. However, pride also has two forms (Tracy \& Robins, 2007b). Authentic pride is elicited when success is attributed to effort and constitutes an immediate positive expression after accomplishments. Hubristic pride is elicited when success is attributed to natural talent. It is displayed more intentionally and less frequently. Plausibly, higher self-other agreement has been found for trait authentic than hubristic pride (Liu et al., 2016). Thus, we expected that only for trait authentic pride, accuracy would be higher than for dispositional envy.

Second, if envy and pride are both related to the regulation of status and more likely to be experienced by the same persons, namely those with a strong orientation towards social status, the social perception of dispositional envy could be confounded with the social perception of trait pride. Therefore, controlling for trait pride in the social perception of dispositional envy would strengthen the conclusion that others can accurately and specifically judge dispositional envy.

\section{Method}

Participants. We approached dyads of passersby near a German university. In total, 508 participants (254 dyads) took part in the study. Three dyads were excluded because a participant either rated a different person than the partner, did not rate the partner at all, or did not provide answers for numerous variables. The mean age of the final sample of 502 participants ( 251 dyads) was 23.7 years ( $S D=3.7$, range: $17-51$; two missing values). There were 33 same-gender male dyads, 147 same-gender female dyads, and 68 mixed-gender dyads (three missing values). The sample size was set a priori with the goal to have 250 dyads, because this allows the estimation of stable correlation coefficients (Schönbrodt \& 
Perugini, 2013). Data collection continued until the end of the day, explaining why we slightly exceeded our goal. Post-hoc power analysis for our more specific analyses indicated that the sample size provided $95 \%$ power to detect small to medium-sized accuracy and bias effects of $\beta=.22$ with $\alpha=.05$ (two-tailed), given common specifications for an APIM with indistinguishable dyads (Ackerman \& Kenny, 2016).

Materials and procedure. Participants rated their dispositional benign and malicious envy on the Benign and Malicious Envy Scale (BeMaS; Lange \& Crusius, 2015a) using a scale from 1 (strongly disagree) to 6 (strongly agree). Subsequently, they completed the Trait Authentic and Hubristic Pride Scale (Tracy \& Robins, 2007b) to assess their trait authentic and hubristic pride on a scale from 1 (not at all) to 5 (extremely). Then, participants rated their partner on the same scales. The scales were all reliable (see Table 3).

Afterwards, participants indicated how well they knew the other person using a scale from 1 (not at all), 2 (fleeting), 3 (rather well), 4 (pretty well) to 5 (very well; $M=3.73, S D=$ 0.79 , range: $1-5 ; 28$ missing values). Moreover, they stated for how many months they had known the partner $(M=29.15, S D=41.03$, range: $1-324 ; 55$ missing values $)$ and how frequently they met using a scale from 1 (less than once a year), 2 (once a year), 3 (once a month), 4 (two to three times a month), 5 (once a week), 6 (multiple times a week) to 7 (daily; $M=5.33, S D=1.25$, range: $1-7 ; 4$ missing values). The three items were $z$-standardized at their grand means and variances and averaged at the dyadic level as an indicator of relationship depth $(\alpha=.79){ }^{1}$

\section{Results}

Table 3 shows descriptive statistics, zero-order correlations for randomly separated partners, and within-dyad correlations. The within-dyad correlations of all variables were positive and mostly significant, indicating dyadic non-independence.

We investigated our predictions with APIMs using structural equation modeling and maximum likelihood estimation. In contrast to Study 1, because partners could not be 
differentiated from each other a priori with respect to a categorizing variable (e.g., whether they won or lost a game), we specified dyadic path models for indistinguishable partners (Kenny et al., 2006). That is, all corresponding paths, means, intercepts, and (co)variances were set equal across partners. All variables were $z$-standardized at their grand means and variances before the analyses. The results of all model tests are displayed in Table 4.

Accuracy and bias. We first specified separate APIMs for each emotional trait (Figure 1). As shown in Table 4, all model fits were satisfactory, applying conventional standards (Hu \& Bentler, 1999). Accuracy coefficients were positive and significant for all four emotional traits. This supports that enviers and proud individuals can be identified. In line with the notion that accuracy should be higher for trait authentic pride than dispositional envy, the $95 \%$ confidence interval of its accuracy coefficient did not include the accuracy coefficient of dispositional malicious envy and vice versa. However, contrary to predictions, it included the accuracy coefficient of dispositional benign envy.

In addition, the bias coefficients for all four emotional traits were positive and significant (Table 4). In fact, the 95\% confidence intervals of the bias coefficients did not include the accuracy coefficients for their respective traits and vice versa, thus indicating significantly stronger bias than accuracy. As also the actual similarities were significantly positive for all emotional traits, self-other agreement was explained to a large degree by a similarity bias for both dispositional envy and trait pride.

The models again allowed for the estimation of self-other agreement from accuracy and the combined effect of bias and actual similarity. As the partners were indistinguishable, the estimates represented self-other agreement averaged across partners. For dispositional benign envy, self-other agreement was $r=.283$, SE $=.049, p<.001,95 \%$ CI [.187, .379], for dispositional malicious envy it was $r=.235, S E=.050, p<.001,95 \%$ CI [.136, .334], for trait authentic pride it was $r=.315, S E=.045, p<.001,95 \%$ CI [.226, .043], and for trait hubristic pride it was $r=.277, S E=.049, p<.001,95 \%$ CI $[.181, .373]$. 
To investigate whether perception accuracies of benign and malicious envy were independent of partners' pride or the respective other envy form, we combined the individual emotion models into a single model. We specified a model with all four emotions simultaneously and constrained all cross-emotion paths to zero, predicting that the social perception of envy is independent from people's pride. Model fit was not satisfactory, $\chi^{2}(96)$ $=238, p<.001, \mathrm{CFI}=.89, \mathrm{RMSEA}=.077 \mathrm{CI} 90 \%[.065 ; .089], \mathrm{SRMR}=.085$. Therefore, we added paths to improve model fit. Because dispositional benign envy was positively correlated with trait authentic pride and dispositional malicious envy with trait hubristic pride (see Table 3), we added actor and partner effects from self-ratings of authentic pride to peerratings of benign envy and from self-ratings of hubristic pride to peer-ratings of malicious envy (see Figure 2). This improved the model fit, $\Delta \chi^{2}(4)=65, p<.001$, and the new model showed acceptable fit to the data, $\chi^{2}(92)=173, p<.001, \mathrm{CFI}=.94, \mathrm{RMSEA}=.059 \mathrm{CI} 90 \%$ $[.045 ; .073]$, SRMR $=.068$. The predicted coefficients were largely unchanged as compared to the individual emotion models. Accuracy was positive for benign envy, $B=0.190, S E=$ $0.036, p<.001, \mathrm{CI} 95 \% B[0.119 ; 0.261]$, malicious envy, $B=0.159, S E=0.032, p<.001$, CI95\% $B$ [0.096; 0.222], authentic pride, $B=0.219, S E=0.039, p<.001$, CI95\% $B[0.143$; 0.295], and hubristic pride, $B=0.192, S E=0.035, p<.001$, CI95\% $B$ [0.123; 0.261]. All four accuracies did not significantly differ from each other. Moreover, there was still substantially more bias for benign envy, $B=0.523, S E=0.036, p<.001$, CI95\% $B$ [0.452; 0.594], malicious envy, $B=0.350, S E=0.032, p<.001$, CI95\% $B[0.287 ; 0.413]$, authentic pride, $B=$ $0.384, S E=0.039, p<.001, \mathrm{CI} 95 \% B[0.308 ; 0.460]$, and hubristic pride, $B=0.512, S E=$ $0.035, p<.001, \mathrm{CI} 95 \% B[0.443 ; 0.581]$ than there was accuracy.

Moderation by relationship depth. To test whether accuracy was higher in closer relationships, we specified separate APIMs in which we included relationship depth and its interaction terms with both partners' self-ratings. Therefore, next to accuracy, bias, and actual 
similarity, this model determined whether accuracy and bias change with increasing levels of relationship depth (Figure 3).

As shown in Table 4, all model fits were satisfactory. The moderation of accuracy by relationship depth was significant for dispositional benign envy. In line with our predictions, accuracy was higher for closer relationships (Figure 4). However, contrary to predictions, there was no significant moderation of accuracy for dispositional malicious envy. The interaction effects of trait authentic and hubristic pride with relationship depth were not significant either. No perception bias was moderated by relationship depth.

\section{Discussion}

Study 2 supports that enviers are identifiable by acquainted partners. Specifically, accuracy coefficients were positive for both dispositional benign and malicious envy as rated by acquainted partners. Furthermore, controlling for pride did not affect perception accuracy of benign or malicious envy. Moreover, the accuracy coefficient of dispositional benign envy was higher in closer relationships. Finally, the accuracy coefficients of trait authentic and hubristic pride were also positive, and for trait authentic pride, the accuracy coefficient was higher than for dispositional malicious envy. Next to accuracy, for all four emotional traits, there was substantial bias. Collectively, accuracy and the combined effect of bias and actual similarity created small to moderate self-other agreement for all emotional traits.

There were, however, two unexpected findings. First, the accuracy coefficient of dispositional malicious envy was not significantly moderated by relationship depth, even though the regression weight of the interaction for malicious envy was not significantly smaller than that for benign envy and the trend was in line with the hypothesis (see Table 4). We speculate that such moderation effects are generally small and difficult to detect. In line with this speculation, previous studies on the role of relationship depth in self-other agreement for emotional traits also found weak evidence for moderation (Watson et al., 2000). In very close relationships it might become more difficult to accurately perceive the 
partner because of halo effects, because partners pay less attention to the other's traits over time as they think they already know each other well, or because partners are interacting only in situations in which the relevant trait is not expressed (for a discussion see Kenny \& Acitelli, 2001). Also, accuracy could reach a plateau after a certain amount of interactions and further relationship experiences might not render new information about the partner's stable dispositions. This may limit the moderating potential of relationship depth. Future studies comparing dyads with a broader variation in relationship depth than realized in this study, especially differentiating new and more established relationships, and comparing multiple contexts that facilitate the expression of envy, are necessary to examine these speculative interpretations.

Second, the accuracy coefficient of trait authentic pride was not significantly higher than that of dispositional benign envy. This may fit theorizing that benign forms of envy are more readily expressed than malicious forms (Foster, 1972). However, accuracy coefficients of dispositional benign and malicious envy did not differ significantly (Table 4). Any conclusion pertaining to diverging effects of the envy forms is therefore tentative. Moreover, it could also be that authentic pride is not as frequently displayed and therefore also not as accurately perceived as we theorized. In fact, people sometimes suppress their pride displays after outperforming in-group members (Van Osch, Zeelenberg, \& Breugelmans, 2016), which could undermine perception accuracy of pride by peers.

\section{General Discussion}

The two studies support that enviers can be identified, but only after extended contact. Specifically, there was no evidence that state envy was accurately perceived in unacquainted dyads after a short interaction including two brief competitions (Study 1). In contrast, dispositional benign and malicious envy, as stable tendencies to react with state envy across multiple situations, were accurately perceived in acquainted dyads, even when controlling for trait pride (Study 2). For dispositional benign but not malicious envy, this 
effect was larger in closer relationships. Across studies, perception bias was stronger than perception accuracy. This is common for the perception of psychological characteristics because people tend to overestimate similarity and are motivated to avoid an accurate perception of the partner if the truth could be threatening (Kenny \& Acitelli, 2001). Thus, it might be difficult or even impossible to accurately perceive envy when observing strangers in particular situations, yet enviers might be identifiable if information across multiple situations can be integrated.

The current results may contribute to research on the experience of being envied. If enviers are identifiable, this suggests that successful people may also be able to perceive by whom they are envied and whether the inferiors' envy is more benign or malicious. Research suggests that being envied is an ambiguous experience (Rodriguez Mosquera et al., 2010; Romani, Grappi, \& Bagozzi, 2016; Van de Ven, Zeelenberg, \& Pieters, 2010). Individuals who are envied may dislike being the target of an upward comparison (Exline \& Lobel, 1999), yet, being envied also implies that one has something of high value. Part of these ambiguous reactions to being envied might be explained by the two envy forms. Benign and malicious envy of inferiors may convey different information to successful people and therefore elicit different affective, cognitive, and motivational consequences. To test this more specifically, future research should investigate how exactly benign and malicious enviers are identified and what information they convey to observers.

Expressive indicators of benign and malicious envy could be investigated with a lens-model approach (Back et al., 2011), linking cues that benign and malicious enviers display across situations with the cues that observers use to infer these inclinations over time. Cue display and cue utilization do not necessarily match, therefore providing insights into the social dynamics of the perception of envy. Longitudinal studies using a lens-model approach may give important insights into how cue utilization changes over the course of relationships to render higher perception accuracy. 
The question how benign and malicious envy are expressed, and which cues perceivers use to recognize it, is also interesting because we did not find consistent differences in accuracy coefficients between trait pride and dispositional envy in Study 2. Although pride has a distinct, cross-culturally recognized expression (Tracy \& Robins, 2007a), accuracy of trait authentic pride was only higher than that of dispositional malicious but not benign envy. Thus, future research may focus on comparing the development of cue utilization between dispositional envy and trait pride in longitudinal studies with new relationship partners. Based on the current findings and rationale, we would expect increasing utilization of valid cues for envy over time. In contrast, pride should be accurately identifiable already at early stages of a relationship.

Although the data support perception accuracy for benign and malicious envy after extended contact, accuracy in the current studies was assessed via a person's self-rating. On the one hand, research implies that for evaluative variables such as envy, self-perception might be distorted. Specifically, peer-ratings can be more accurate than self-ratings, if behavioral reactions are used as a benchmark for assessing accuracy (Vazire, 2010). On the other hand, the same research also supports that for internal variables, behavioral reactions are more strongly related to self-ratings. Emotions are by definition internal variables and given the lack of a distinct display of envy, it may be even more internal than many other emotions. Thus, in future research, it would be interesting to investigate self- and peer-reports in relation to envious behavior to determine whether the self or peers are more accurate regarding behavioral criteria. In line with our theorizing, this research may also consider assessing the contingencies of multiple cues, which may provide more insights into the accuracy in the social perception of envy (for a similar approach see Dufner, Arslan, Hagemeyer, Schönbrodt, \& Denissen, 2015).

Moreover, perception accuracy of envy in the APIM was supported only for dispositional envy in Study 2, but not for state envy after a short interaction in Study 1. We 
interpret this as evidence that dispositional envy integrates state envy across multiple situations, facilitating the perception of contingencies between contextual and personal cues to envy. However, three related objections can be put forward against this interpretation. A first objection might be that partners may use other cues related to envy such as a person's self-esteem or neuroticism to infer dispositional envy. However, evidence supports that dispositional envy predicts state envy even when taking self-esteem, neuroticism, social desirability, hostility, and other emotions into account (Rentzsch \& Gross, 2015; Smith et al., 1999). In line with this, Study 2 supported that even after controlling for trait pride, another status-relevant emotional trait, the accuracy coefficient of dispositional envy remained significantly positive. Additionally, any study on the perception of state envy would also suffer from the limitation that partners may rely on other, related cues such as self-esteem or neuroticism in their judgements. Research on trait judgements at zero acquaintance supports that self-esteem and neuroticism can be accurately perceived by strangers based on thin slices of behavior (e.g., Carney, Colvin, \& Hall, 2007; Hirschmüller, Schmukle, Krause, Back, \& Egloff, 2018). Therefore, if the perception of dispositional envy was confounded with selfesteem or neuroticism, we would have likely found perception accuracy due to the same confounding for state envy in Study 1. Thus, our findings are more consistent with the hypothesis that it takes repeated observations to accurately identify enviers than it is with the notion that other variables drove perception accuracy in the APIM. Still, ruling out such confounding variables directly constitutes a valuable goal for future research.

A second objection might be that accurate identification of dispositional enviers in Study 2 resulted from other sources than the perception of envy across situations. For instance, dyad members may share information about their envy experiences, leading them to accurately rate each other's disposition. Yet, envy would have never been perceived directly. Although we deem it unlikely that enviers hide their feelings across situations, but then share them in interactions, future research may address this question. This would require 
unacquainted dyads who cannot have such information about their partners. Then, these unacquainted dyad partners would need to interact for a long period of time across various situations that elicit different levels of envy.

A third objection might be that the different results for state and dispositional envy resulted from the fact that we measured state envy in Study 1 with items focusing on the emotion label, whereas we measured dispositional envy in Study 2 with items focusing on benign and malicious manifestations of envy. Although we cannot rule out that this explains the pattern of results, we think it is unlikely. The emotion label envy captures all affective, cognitive, and motivational components envy entails (Lange et al., 2018) and questionnaires relying on the label are positively correlated with other measures that assess specific components of envy (Lange \& Crusius, 2015b; Van de Ven, 2016). Therefore, the state envy measure in Study 1 puts no restriction on what kinds of cues partners could have used to accurately perceive the other's envy. As envy is typically disguised and can manifest in various different ways (Smith \& Kim, 2007), such an encompassing measure should have, if anything, increased the chances of finding accuracy. In contrast, the focus on the benign and malicious manifestations of envy in Study 2 may have undermined it, because partners' envy could manifest in slightly different ways not assessed by these items. Thus, we think that the different measurement strategies may have even worked against our hypotheses.

Nevertheless, future research should test the social perception of state and dispositional envy with measures assessing different components to compare their effects.

In sum, the current investigation provides evidence that benign and malicious enviers are identifiable but only after extended contact. We hope that this renews the interest in investigating the social perception of envy. 


\section{References}

Ackerman, R. A., \& Kenny, D. A. (2016). APIMPower: An interactive tool for Actor-Partner Interdependence Model power analysis. Retrieved from https://robert-aackerman.shinyapps.io/apimpower/

Anderson, C., Hildreth, J. A. D., \& Howland, L. (2015). Is the desire for status a fundamental human motive? A review of the empirical literature. Psychological Bulletin, 141, 574 601. http://doi.org/10.1037/a0038781

Back, M. D., Baumert, A., Denissen, J. J. A., Hartung, F.-M., Penke, L., Schmukle, S. C., ... Wrzus, C. (2011). PERSOC: A unified framework for understanding the dynamic interplay of personality and social relationships. European Journal of Personality, 25, 90-107. http://doi.org/10.1002/per.811

Carney, D. R., Colvin, C. R., \& Hall, J. A. (2007). A thin slice perspective on the accuracy of first impressions. Journal of Research in Personality, 41, 1054-1072. http://doi.org/10.1016/j.jrp.2007.01.004

Crusius, J., \& Lange, J. (2017). How do people respond to threatened social status? Moderators of benign versus malicious envy. In R. H. Smith, U. Merlone, \& M. K. Duffy (Eds.), Envy at work and in organizations: Research, theory, and applications (pp. 85-110). New York, NY: Oxford University Press.

Dufner, M., Arslan, R. C., Hagemeyer, B., Schönbrodt, F. D., \& Denissen, J. J. A. (2015). Affective contingencies in the affiliative domain: Physiological assessment, associations with the affiliation motive, and prediction of behavior. Journal of Personality and Social Psychology, 109, 662-676. http://doi.org/10.1037/pspp0000025

Exline, J. J., \& Lobel, M. (1999). The perils of outperformance: Sensitivity about being the target of a threatening upward comparison. Psychological Bulletin, 125, 307-337. http://doi.org/10.1037/0033-2909.125.3.307 
Falcon, R. G. (2015). Is envy categorical or dimensional? An empirical investigation using taxometric analysis. Emotion, 15, 694-698. http://doi.org/10.1037/emo0000102

Fiske, S. T. (2010). Envy up, scorn down: How comparison divides us. American Psychologist, 65, 698-706. http://doi.org/10.1037/0003-066X.65.8.698

Fleeson, W., \& Jayawickreme, E. (2015). Whole Trait Theory. Journal of Research in Personality, 56, 82-92. http://doi.org/10.1016/j.jrp.2014.10.009

Foster, G. M. (1972). The anatomy of envy: A study in symbolic behavior. Current Anthropology, 13, 165-202. http://doi.org/10.1086/201267

Hirschmüller, S., Schmukle, S. C., Krause, S., Back, M. D., \& Egloff, B. (2018). Accuracy of self-esteem judgments at zero acquaintance. Journal of Personality, 86, 308-319. http://doi.org/10.1111/jopy.12316

Hu, L., \& Bentler, P. M. (1999). Cutoff criteria for fit indexes in covariance structure analysis: Conventional criteria versus new alternatives. Structural Equation Modeling: A Multidisciplinary Journal, 6, 1-55. http://doi.org/10.1080/10705519909540118

Kenny, D. A., \& Acitelli, L. K. (2001). Accuracy and bias in the perception of the partner in a close relationship. Journal of Personality and Social Psychology, 80, 439-448. http://doi.org/10.1037//0022-3514.80.3.439

Kenny, D. A., Kashy, D. A., \& Cook, W. L. (2006). Dyadic data analysis. New York, NY: Guilford Press.

Lange, J., \& Crusius, J. (2015a). Dispositional envy revisited: Unraveling the motivational dynamics of benign and malicious envy. Personality and Social Psychology Bulletin, 41, 284-294. http://doi.org/10.1177/0146167214564959

Lange, J., \& Crusius, J. (2015b). The tango of two deadly sins: The social-functional relation of envy and pride. Journal of Personality and Social Psychology, 109, 453-472. http://doi.org/10.1037/pspi0000026 
Lange, J., Crusius, J., \& Hagemeyer, B. (2016). The Evil Queen's dilemma: Linking narcissistic admiration and rivalry to benign and malicious envy. European Journal of Personality, 30, 168-188. http://doi.org/10.1002/per.2047

Lange, J., Weidman, A. C., \& Crusius, J. (2018). The painful duality of envy: Evidence for an integrative theory and a meta-analysis on the relation of envy and schadenfreude. Journal of Personality and Social Psychology, 114, 572-598. http://doi.org/10.1037/pspi0000118

Liu, C., Yuan, L., Chen, C., \& Yu, G. (2016). Authentic and hubristic pride as assessed by self, friends, and strangers. Social Psychological and Personality Science, 7, 690-696. http://doi.org/10.1177/1948550616649240

Miceli, M., \& Castelfranchi, C. (2007). The envious mind. Cognition \& Emotion, 21, 449479. http://doi.org/10.1080/02699930600814735

Neyer, F. J., Banse, R., \& Asendorpf, J. B. (1999). The role of projection and empathic accuracy in dyadic perception between older twins. Journal of Social and Personal Relationships, 16, 419-442. http://doi.org/10.1177/0265407599164001

Niedenthal, P., \& Ric, F. (2017). Psychology of emotion. New York: Routledge.

Rentzsch, K., \& Gross, J. J. (2015). Who turns green with envy? Conceptual and empirical perspectives on dispositional envy. European Journal of Personality, 29, 530-547. http://doi.org/10.1002/per.2012

Rentzsch, K., \& Lösch, T. (2018). PESI (Personality and Emotions in Social Interactions). Retrieved from osf.io/2uf7a

Robins, R. W., \& Beer, J. S. (2001). Positive illusions about the self: Short-term benefits and long-term costs. Journal of Personality and Social Psychology, 80, 340-352. http://doi.org/10.1037//0022-3514.80.2.340

Rodriguez Mosquera, P. M., Parrott, W. G., \& Hurtado de Mendoza, A. (2010). I fear your envy, I rejoice in your coveting: On the ambivalent experience of being envied by 
others. Journal of Personality and Social Psychology, 99, 842-854. http://doi.org/10.1037/a0020965

Rogoza, R., Kwiatkowska, M. M., Kowalski, C. M., \& Ślaski, S. (2018). A brief tale of the two faces of narcissism and the two facets of pride. Personality and Individual Differences, 126, 104-108. http://doi.org/10.1016/j.paid.2018.01.027

Romani, S., Grappi, S., \& Bagozzi, R. P. (2016). The bittersweet experience of being envied in a consumption context. European Journal of Marketing, 50, 1239-1262. http://doi.org/10.1108/EJM-03-2015-0133

Schönbrodt, F. D., \& Perugini, M. (2013). At what sample size do correlations stabilize? Journal of Research in Personality, 47, 609-612. http://doi.org/10.1016/j.jrp.2013.05.009

Shariff, A. F., \& Tracy, J. L. (2009). Knowing who's boss: Implicit perceptions of status from the nonverbal expression of pride. Emotion, 9, 631-639. http://doi.org/10.1037/a0017089

Silver, M., \& Sabini, J. (1978). The perception of envy. Social Psychology, 41, 105-117. http://doi.org/10.2307/3033570

Smith, R. H. (2004). Envy and its transmutations. In L. Z. Tiedens \& C. Leach (Eds.), The social life of emotions (pp. 43-63). Cambridge: Cambridge University Press.

Smith, R. H., \& Kim, S. H. (2007). Comprehending envy. Psychological Bulletin, 133, 46-64. http://doi.org/10.1037/0033-2909.133.1.46

Smith, R. H., Parrott, W. G., Diener, E. F., Hoyle, R. H., \& Kim, S. H. (1999). Dispositional envy. Personality and Social Psychology Bulletin, 25, 1007-1020. http://doi.org/10.1177/01461672992511008

Tracy, J. L., \& Robins, R. W. (2007a). The prototypical pride expression: Development of a nonverbal behavior coding system. Emotion, 7, 789-801. http://doi.org/10.1037/15283542.7.4.789 
Tracy, J. L., \& Robins, R. W. (2007b). The psychological structure of pride: A tale of two facets. Journal of Personality and Social Psychology, 92, 506-525. http://doi.org/10.1037/0022-3514.92.3.506

Van de Ven, N. (2016). Envy and its consequences: Why it is useful to distinguish between benign and malicious envy. Social and Personality Psychology Compass, 10, 337349. http://doi.org/10.1111/spc3.12253

Van de Ven, N., Zeelenberg, M., \& Pieters, R. (2009). Leveling up and down: The experiences of benign and malicious envy. Emotion, 9, 419-429. http://doi.org/10.1037/a0015669

Van de Ven, N., Zeelenberg, M., \& Pieters, R. (2010). Warding off the evil eye: When the fear of being envied increases prosocial behavior. Psychological Science, 21, 16711677. http://doi.org/10.1177/0956797610385352

Van Osch, Y., Zeelenberg, M., \& Breugelmans, S. M. (2016). On the context dependence of emotion displays: Perceptions of gold medalists' expressions of pride. Cognition and Emotion, 30, 1332-1343. http://doi.org/10.1080/02699931.2015.1063480

Vazire, S. (2010). Who knows what about a person? The self-other knowledge asymmetry (SOKA) model. Journal of Personality and Social Psychology, 98, 281-300. http://doi.org/10.1037/a0017908

Watson, D., Hubbard, B., \& Wiese, D. (2000). Self-other agreement in personality and affectivity: The role of acquaintanceship, trait visibility, and assumed similarity. Journal of Personality and Social Psychology, 78, 546-558. http://doi.org/10.1037//0022-3514.78.3.546 


\section{Footnotes}

${ }^{1}$ We also included ad hoc scales measuring how frequently partners met in status or affiliation related situations in general and in specific status and affiliation related situations. The general situation measures were not highly correlated with relationship depth, casting doubt on their validity. All specific situation variables loaded on a single factor, rendering it statistically implausible to create separate variables for status and affiliation. Thus, we refrained from analyzing these data. 
Table 1

Zero-order Correlations for Both Partners and Within-Dyad Correlations in Study 1

$$
M_{\text {Winner }}(S D) \quad M_{\text {Loser }}(S D) \quad \text { Cronbach's } \quad \text { Envy RPS }
$$

Envy LOTM

Rating of

other's envy

RPS

$\begin{array}{llllll}1.30(0.61) & 2.26(1.40) & .89 & .10 & .73^{*} & .17^{*} \\ 1.43(0.73) & 1.57(0.89) & .83 & .63^{*} & -.03 & .37^{*} \\ 2.32(1.27) & 1.33(0.59) & .87 & .03 & .21^{*} & -.10 \\ 1.43(0.67) & 1.43(0.70) & .81 & .26^{*} & .37^{*} & .52^{*}\end{array}$

$52 *$

$\begin{array}{cccc}\text { Envy RPS } & 1.30(0.61) & 2.26(1.40) & .89 \\ \text { Envy LOTM } & 1.43(0.73) & 1.57(0.89) & .83 \\ \text { of other's envy RPS } & 2.32(1.27) & 1.33(0.59) & .87 \\ \text { of other's envy LOTM } & 1.43(0.67) & 1.43(0.70) & .81\end{array}$

Rating of other's envy LOTM

$.35^{*}$

$.55^{*}$ .00

Note. $N=436$. Zero-order correlations for both partners. Winner of the rock-paper-scissors game (above diagonal) and Loser of the rock-paperscissors game (below diagonal) with $n=218$. Within-dyad correlations in italics on diagonal with $n=218$ dyads. Two missing values for Envy RPS, 16 missing values for Rating of other's envy RPS, and 11 missing values for Rating of other's envy LOTM. RPS = rock-paper-scissors game, LOTM $=$ lost-on-the-moon task

Responses were provided on a scale from 1 (does not apply at all) to 7 (applies strongly).

$* p<.05$ 
Table 2

Results of Model Tests in Study 1

$\begin{array}{rrrr}B / r \quad S E & p & B / r \text { CI } 95 \% & \chi^{2}(d f) \\ & \text { Rock-Paper-Scissors Game }\end{array}$

\begin{tabular}{|c|c|c|c|c|c|c|c|c|}
\hline & & & & & $\chi^{2}(1)=0.30, p=.58$ & 1.00 & $.000[.000 ; .146]$ & .010 \\
\hline Winner's Accuracy & 0.040 & 0.049 & .406 & $-0.055 ; 0.136$ & & & & \\
\hline Winner's Bias & 0.355 & 0.149 & .017 & $0.063 ; 0.646$ & & & & \\
\hline Loser's Accuracy & 0.040 & 0.049 & .406 & $-0.055 ; 0.136$ & & & & \\
\hline Loser's Bias & 0.015 & 0.032 & .633 & $-0.048 ; 0.078$ & & & & \\
\hline Actual Similarity & .059 & .042 & .156 & $-.023 ; .141$ & & & & \\
\hline
\end{tabular}

\section{Lost-On-The-Moon Task}

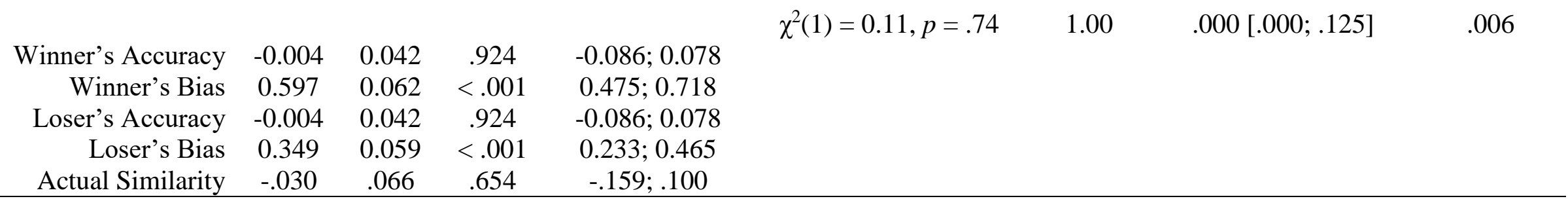

Note. $N=218$ dyads. All variables were $z$-standardized at their grand means and variances. Missing data were treated with Full Information Maximum Likelihood Estimation. The model is depicted in Figure 1. Winner = participant who won the rock-paper-scissors game, Loser $=$ participant who lost the rock-paper-scissors game 
Table 3

Zero-order Correlations for Randomly Separated Partners and Within-Dyad Correlations in Study 2

\begin{tabular}{|c|c|c|c|c|c|c|c|c|c|c|}
\hline & $M(S D)$ & Cronbach's $\alpha$ & $\begin{array}{l}\text { Dispositional } \\
\text { benign envy }\end{array}$ & $\begin{array}{c}\text { Dispositional } \\
\text { malicious envy }\end{array}$ & $\begin{array}{c}\text { Trait authentic } \\
\text { pride }\end{array}$ & $\begin{array}{c}\text { Trait hubristic } \\
\text { pride }\end{array}$ & $\begin{array}{l}\text { Rating of other's } \\
\text { benign envy }\end{array}$ & $\begin{array}{c}\text { Rating of other's } \\
\text { malicious envy }\end{array}$ & $\begin{array}{l}\text { Rating of other's } \\
\text { authentic pride }\end{array}$ & $\begin{array}{l}\text { Rating of other's } \\
\text { hubristic pride }\end{array}$ \\
\hline $\begin{array}{l}\text { Dispositional } \\
\text { benign envy }\end{array}$ & $3.55(0.98)$ & .78 & $.15 *$ & $.15^{*}$ & $.18^{*}$ & $.11^{+}$ & $.56^{*}$ & $.14^{*}$ & $.17 *$ & .09 \\
\hline $\begin{array}{l}\text { Dispositional } \\
\text { malicious envy }\end{array}$ & $1.96(0.91)$ & .84 & $.18^{*}$ & $.13 *$ & $-.27^{*}$ & $.41^{*}$ & $.25 *$ & $.57 *$ & $-.26^{*}$ & $.41 *$ \\
\hline $\begin{array}{l}\text { Trait authentic } \\
\text { pride }^{\mathrm{b}}\end{array}$ & $3.62(0.55)$ & .78 & $.22 *$ & $-.24 *$ & $.20^{*}$ & $.11^{+}$ & .04 & -.10 & $.40 *$ & -.04 \\
\hline $\begin{array}{l}\text { Trait hubristic } \\
\text { pride }^{\mathrm{b}}\end{array}$ & $2.02(0.59)$ & .77 & .10 & $.29 *$ & $.11^{+}$ & $.14 *$ & .01 & $.45^{*}$ & $-.13^{*}$ & $.54 *$ \\
\hline $\begin{array}{l}\text { Rating of other's } \\
\text { benign envy }\end{array}$ & $3.41(0.98)$ & .84 & $.55^{*}$ & $.20^{*}$ & $.12 *$ & $.13^{*}$ & $.20^{*}$ & $.23^{*}$ & $.16^{*}$ & $.14^{*}$ \\
\hline $\begin{array}{l}\text { Rating of other's } \\
\text { malicious envy }\end{array}$ & $1.73(0.86)$ & .88 & .10 & $.59 *$ & $-.12^{+}$ & $.40 *$ & $.27 *$ & $.31 *$ & $-.30 *$ & $.63 *$ \\
\hline $\begin{array}{l}\text { Rating of other's } \\
\text { authentic pride }^{\mathrm{b}}\end{array}$ & $3.86(0.58)$ & .84 & .08 & $-.27 *$ & $.42 *$ & -.06 & $.18^{*}$ & $-.26^{*}$ & .10 & $-.11^{+}$ \\
\hline $\begin{array}{l}\text { Rating of other's } \\
\text { hubristic pride }^{\mathrm{b}}\end{array}$ & $1.77(0.58)$ & .80 & -.03 & $.30 *$ & -.08 & $.56^{*}$ & $.21 *$ & $.53 *$ & -.02 & $.26^{*}$ \\
\hline
\end{tabular}

Note. $N=502$. Zero-order correlations for randomly separated partners. Partner 1 (above diagonal) and Partner 2 (below diagonal) with $n=251$.

Within-dyad correlations in italics on diagonal with $n=251$ dyads.

${ }^{\text {a }}$ Participants self-rated scores or the ratings of their partners on the Benign and Malicious Envy Scale (BeMaS; Lange \& Crusius, 2015a).

Responses were provided on a scale from 1 (strongly disagree) to 6 (strongly agree).

${ }^{\mathrm{b}}$ Participants self-rated scores or the ratings of their partners on the Trait Authentic and Hubristic Pride Scale (Tracy \& Robins, 2007b). Responses were provided on a scale from 1 (not at all) to 5 (extremely).

$* p<.05,{ }^{+} p<.10$ 
Table 4

Results of Model Tests in Study 2

\begin{tabular}{|c|c|c|c|c|c|c|c|c|}
\hline \multirow[b]{2}{*}{ Emotion } & \multirow[b]{2}{*}{$B / r$} & \multirow[b]{2}{*}{$S E$} & \multirow[b]{2}{*}{$p$} & \multirow[b]{2}{*}{$B / r \mathrm{CI} 95 \%$} & \multicolumn{4}{|c|}{ Model Fit } \\
\hline & & & & & $\chi^{2}(d f)$ & CFI & RMSEA [CI 90\%] & SRMR \\
\hline \multicolumn{9}{|c|}{ Accuracy and Bias } \\
\hline Benign Envy & & & & & $\chi^{2}(6)=1.97, p=.92$ & 1.00 & $.000[.000 ; .028]$ & .022 \\
\hline Accuracy & 0.204 & 0.037 & $<.001$ & $0.131 ; 0.277$ & & & & \\
\hline Bias & 0.525 & 0.037 & $<.001$ & $0.452 ; 0.598$ & & & & \\
\hline Actual Similarity & .150 & .064 & .018 & $.025 ; .275$ & & & & \\
\hline Malicious Envy & & & & & $\chi^{2}(6)=3.62, p=.73$ & 1.00 & $.000[.000 ; .060]$ & .034 \\
\hline Accuracy & 0.164 & 0.036 & $<.001$ & $0.093 ; 0.235$ & & & & \\
\hline Bias & 0.556 & 0.036 & $<.001$ & $0.485 ; 0.627$ & & & & \\
\hline Actual Similarity & .129 & .064 & .043 & $.004 ; .254$ & & & & \\
\hline Authentic Pride & & & & & $\chi^{2}(6)=9.96, p=.13$ & .97 & $.051[.000 ; .106]$ & .047 \\
\hline Accuracy & 0.245 & 0.041 & $<.001$ & $0.165 ; 0.325$ & & & & \\
\hline Bias & 0.359 & 0.041 & $<.001$ & $0.279 ; 0.439$ & & & & \\
\hline Actual Similarity & .194 & .064 & .002 & $.069 ; .319$ & & & & \\
\hline Hubristic Pride & & & & & $\chi^{2}(6)=11.94, p=.06$ & .97 & $.063[.000 ; .115]$ & .077 \\
\hline Accuracy & 0.207 & 0.037 & $<.001$ & $0.134 ; 0.280$ & & & & \\
\hline Bias & 0.518 & 0.037 & $<.001$ & $0.445 ; 0.591$ & & & & \\
\hline Actual Similarity & .135 & .064 & .034 & $.010 ; .260$ & & & & \\
\hline \multicolumn{9}{|c|}{ Moderation by Relationship Depth } \\
\hline Benign Envy & & & & & $\chi^{2}(15)=21.20, p=.13$ & .98 & $.041[.000 ; .077]$ & .051 \\
\hline Accuracy & 0.200 & 0.037 & $<.001$ & $0.129 ; 0.275$ & & & & \\
\hline Bias & 0.517 & 0.037 & $<.001$ & $0.444 ; 0.560$ & & & & \\
\hline
\end{tabular}




\begin{tabular}{|c|c|c|c|c|c|c|c|c|}
\hline Actual Similarity & .150 & .064 & .018 & $.025 ; .275$ & & & & \\
\hline Relationship & 0.057 & 0.047 & .232 & $-0.035 ; 0.149$ & & & & \\
\hline Interaction Acc X Rel & 0.104 & 0.050 & .038 & $0.006 ; 0.202$ & & & & \\
\hline Interaction Bias X Rel & -0.004 & 0.050 & .937 & $-0.102 ; 0.094$ & & & & \\
\hline Malicious Envy & & & & & $\chi^{2}(15)=21.31, p=.13$ & .98 & $.041[.000 ; .078]$ & .050 \\
\hline Accuracy & 0.174 & 0.036 & $<.001$ & $0.103 ; 0.245$ & & & & \\
\hline Bias & 0.548 & 0.036 & $<.001$ & $0.477 ; 0.619$ & & & & \\
\hline Actual Similarity & .129 & .064 & .043 & $.004 ; .254$ & & & & \\
\hline Relationship & 0.079 & 0.053 & .132 & $-0.025 ; 0.187$ & & & & \\
\hline Interaction Acc X Rel & 0.081 & 0.054 & .132 & $-0.025 ; 0.187$ & & & & \\
\hline Interaction Bias X Rel & -0.076 & 0.054 & .157 & $-0.182 ; 0.030$ & & & & \\
\hline Authentic Pride & & & & & $\chi^{2}(15)=17.42, p=.30$ & .99 & $.025[.000 ; .067]$ & .043 \\
\hline Accuracy & 0.259 & 0.041 & $<.001$ & $0.179 ; 0.339$ & & & & \\
\hline Bias & 0.368 & 0.041 & $<.001$ & $0.288 ; 0.448$ & & & & \\
\hline Actual Similarity & .194 & .064 & .002 & $.069 ; .319$ & & & & \\
\hline Relationship & -0.110 & 0.050 & .030 & $-0.208 ;-0.012$ & & & & \\
\hline Interaction Acc X Rel & 0.057 & 0.065 & .380 & $-0.070 ; 0.184$ & & & & \\
\hline Interaction Bias X Rel & -0.066 & 0.065 & .312 & $-0.193 ; 0.061$ & & & & \\
\hline Hubristic Pride & & & & & $\chi^{2}(15)=30.67, p=.01$ & .94 & $.065[.031 ; .097]$ & .068 \\
\hline Accuracy & 0.202 & 0.037 & $<.001$ & $0.129 ; 0.275$ & & & & \\
\hline Bias & 0.511 & 0.037 & $<.001$ & $0.438 ; 0.584$ & & & & \\
\hline Actual Similarity & .135 & .064 & .034 & $.010 ; .260$ & & & & \\
\hline Relationship & 0.102 & 0.049 & .038 & $0.006 ; 0.198$ & & & & \\
\hline Interaction Acc X Rel & 0.057 & 0.051 & .269 & $-0.043 ; 0.157$ & & & & \\
\hline Interaction Bias X Rel & 0.039 & 0.051 & .449 & $-0.061 ; 0.139$ & & & & \\
\hline
\end{tabular}

Note. $N=251$ dyads. All variables were $z$-standardized at their grand means and variances. The models are depicted in Figures 1 and 2. Acc $=$ Accuracy, Rel = Relationship 


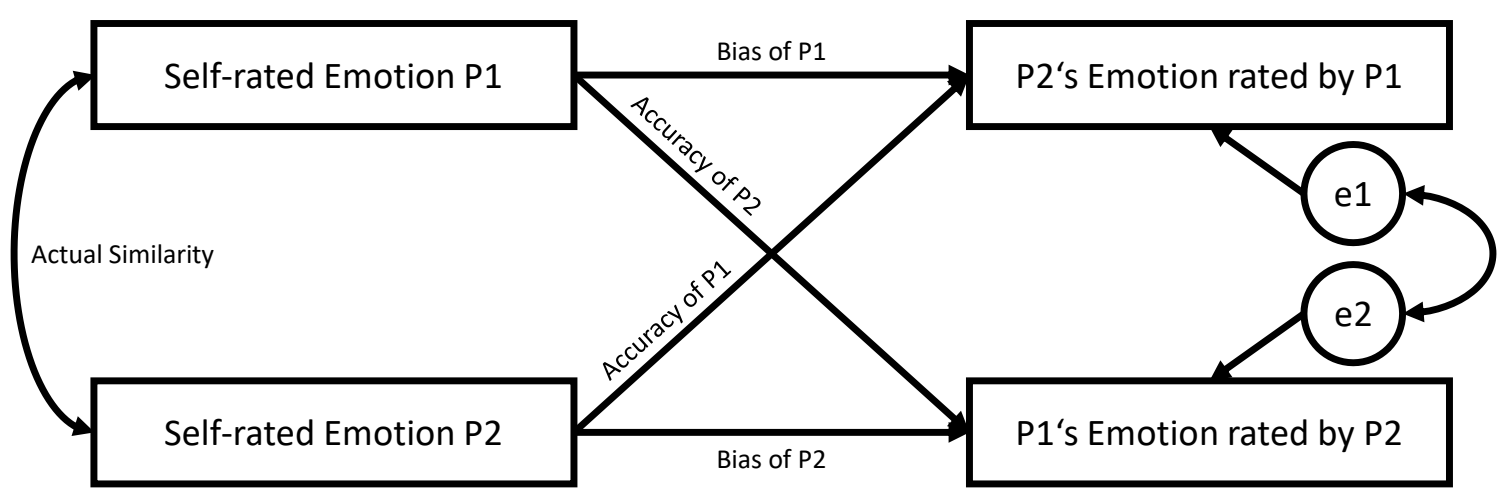

Figure 1. Actor-Partner Interdependence Model tested for individual emotions and interpretation of central coefficients. Corresponding, paths, means, intercepts, and variances were initially estimated freely in Study 1 and set equal between partners in Study 2. $\mathrm{P}=$ Partner 


\begin{tabular}{|l|l|}
\hline Self-rated Benign Envy P1 \\
\hline Self-rated Malicious Envy P1 \\
\hline Self-rated Authentic Pride P1 \\
\hline Self-rated Hubristic Pride P1 \\
\hline Self-rated Malicious Envy P2 \\
\hline Self-rated Authentic Pride P2 \\
\hline Self-rated Hubristic Pride P2
\end{tabular}

Figure 2. Actor-Partner Interdependence Model with all emotions included simultaneously in Study 2. Solid paths were part of the initial model. Dotted paths were added to improve fit. Covariances between exogenous variables and between error terms of endogenous variables as well as error terms themselves were omitted for clarity.

Corresponding paths, means, intercepts, and (co)variances were set equal between partners. $\mathrm{P}$ $=$ Partner 


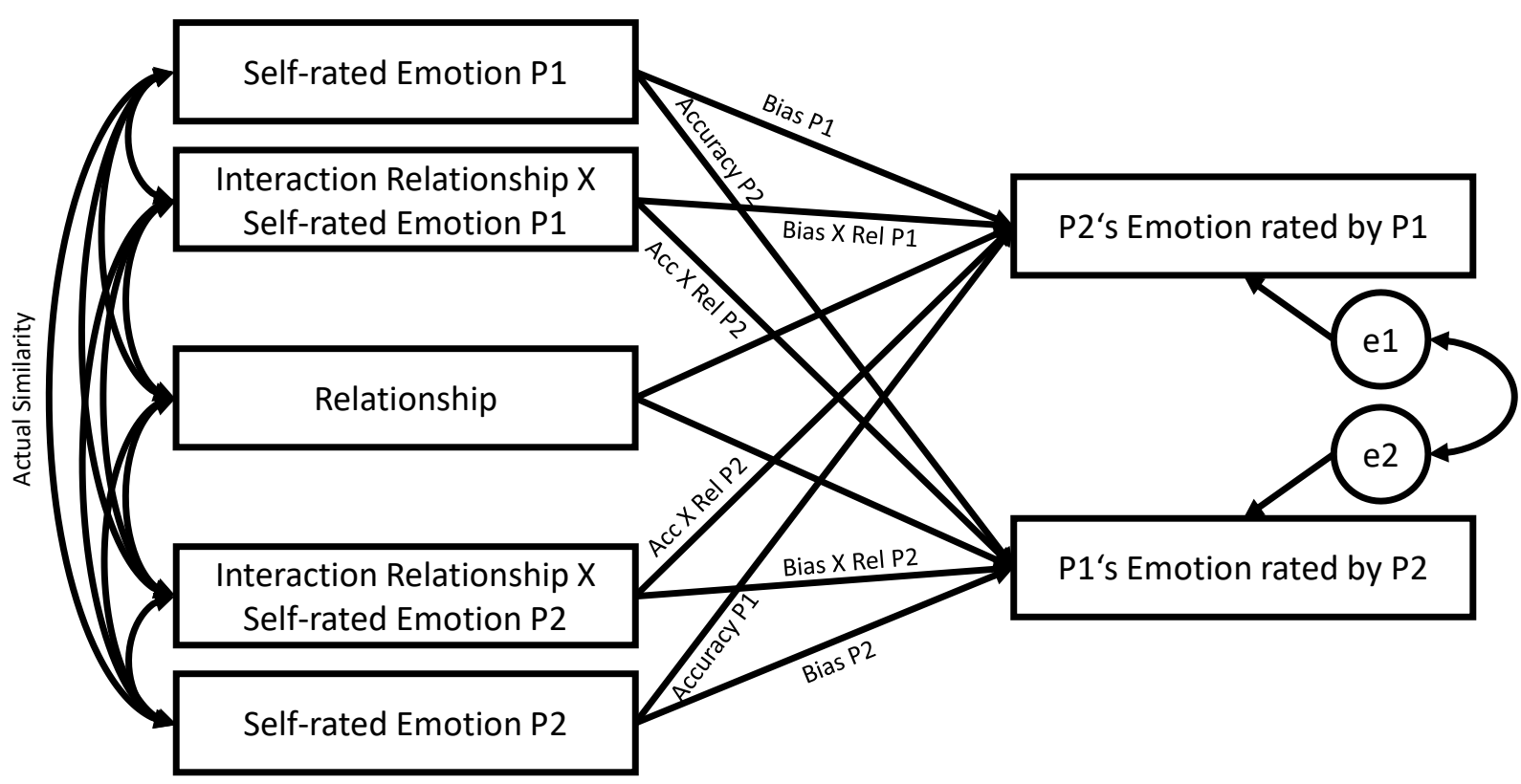

Figure 3. Actor-Partner Interdependence Model tested for the interaction with relationship depth for emotional traits in Study 2 and interpretation of central coefficients. Corresponding, paths, means, intercepts, and (co)variances were set equal between partners. P $=$ Partner, Acc $=$ Accuracy, Rel $=$ Relationship Depth 


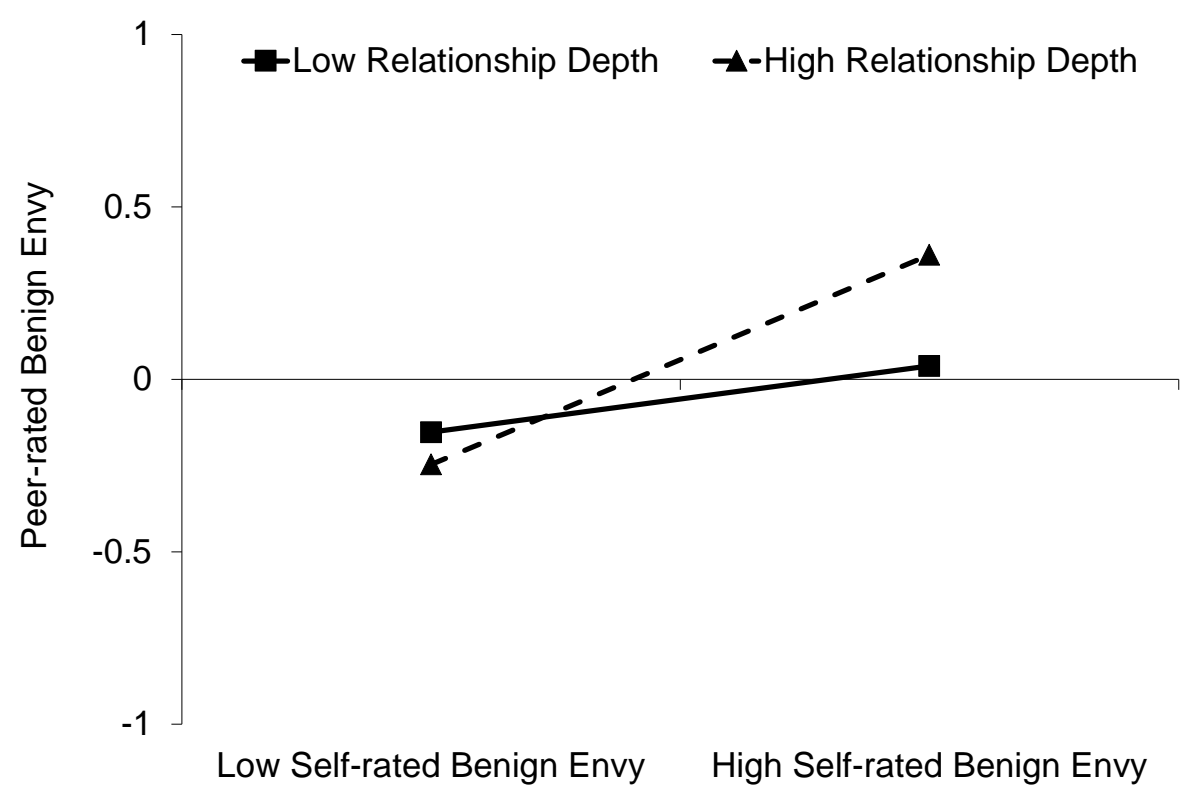

Figure 4. Interaction effect of perception accuracy with relationship depth for dispositional benign envy in Study 2. Slopes represent regression coefficients of variables that were $z$-standardized at their sample grand means and variances. High/low values represent $M$ $\pm 1 S D$. 